\title{
Investigation of Filling Phase Percentages on the Performance of WC-Cu Based Hot-Pressing Diamond Bit Matrices
}

\author{
Songcheng Tan ${ }^{1}(0)$, Changping $\mathrm{Li}^{2,3}{ }^{2}$, Xiaohong Fang ${ }^{1, *} \mathbb{C}$, Hengchao Shi ${ }^{1}$, Longchen Duan ${ }^{1}$ \\ and Chenglong $\mathrm{Li}^{1}$ \\ 1 Faculty of Engineering, China University of Geosciences, Wuhan 430074, China; \\ wstansongcheng@cug.edu.cn (S.T.); shc@cug.edu.cn (H.S.); duanlongchen@163.com (L.D.); \\ wslcl153@163.com (C.L.) \\ 2 School of Mechanical Engineering and Electronic Information, China University of Geosciences, \\ Wuhan 430074, China; lichangpingcug@126.com \\ 3 School of Automation, China University of Geosciences, Wuhan 430074, China \\ * Correspondence: duyaoff@163.com; Tel.: +86-27-6788-3507
}

Received: 5 November 2019; Accepted: 29 November 2019; Published: 3 December 2019

\begin{abstract}
WC-Cu based hot-pressing diamond bit has been widely applied in all-hydraulic geological exploration, as well as deep and ultra-deep well drilling in the oil and gas industry. However, the effect laws and mechanisms of $\mathrm{Cu}$ and WC on the metal matrix composite need further study. Therefore, six WC-Cu based metal matrices were designed, and a series of samples with different dimensions were fabricated to conduct some specific physical and mechanical tests, namely, tests of relative density, Rockwell hardness, bending strength, impact toughness and abrasion weight loss. Additionally, the microstructure and diamond retention conditions of the WC-Cu based samples after bending strength test, as well as their wear morphologies after the pin-on-disc wear test, were analyzed by scanning electron microscope. Test results indicate that most of the physical and mechanical properties were improved with the increase of $663-\mathrm{Cu}$ at first, and then monotonously declined. The increase of $663-\mathrm{Cu}$ also shows an important influence on the samples' microstructure, diamond retention capacity and wear mechanism.
\end{abstract}

Keywords: metal matrix composite; diamond tools; diamond retention; pin-on-disc wear; powder metallurgy

\section{Introduction}

Metal based diamond tools can obtain stronger mechanical properties compared with resin and ceramic based tools, and thus have been widely applied in oil and gas drilling, mineral resources exploration, geotechnical investigation and surveying, repair and reconstruction for reinforced concrete structures, etc. [1-4]. Those diamond tools typically include impregnated diamond bits, saws, wires and wheels [5-8], all of which can be employed for some specific industries and environments. Consequently, specially selected powder metallurgy materials composition is the key to improving diamond tools' service performance $[9,10]$.

Nitkiewicz and Swierzy [11] found that tin in metal matrix composition can improve diamond tools' hardness and densification. del Villar et al. [12] studied two grades of $\mathrm{Cu}-\mathrm{Co}-\mathrm{Fe}$ based alloys for diamond tools production. Test results indicate that the hardness of the samples depends on their applied fabrication route, while copper plastic flow is the dominant densification mechanism during hot pressing. Spriano et al. [13] investigated the feasibility of several titanium alloys (Co-Ti-Ni-Al) as diamond tools matrices, and composite samples were obtained with high relative density, strong 
diamond-metal interface and no graphitization on diamond particles surfaces. Zak-Szwed et al. [14] studied the effects of powder composition and consolidation conditions on the microstructure and mechanical properties when pre-alloyed $\mathrm{Fe}-\mathrm{Cu}$ and $\mathrm{Fe}-\mathrm{Cu}-\mathrm{Sn}-\mathrm{Sm}_{2} \mathrm{O}_{3}$ powders were used as matrices for impregnated diamond tools. The specimens obtained the best performance of high hardness, yield strength and ductility at the sintering temperature of $900^{\circ} \mathrm{C}$. Furthermore, partially pre-alloyed iron based diamond tool matrix can obtain higher hardness and bend strength $[15,16]$.

To find out novel metallic binders and reduce cobalt content in diamond tools, Loginov et al. [17] designed novel Fe-Co-Ni binders doped with $\mathrm{Ti}$ and $\mathrm{TiH}_{2}$ to improve cutting tools' mechanical properties and adhesion to diamond grits. Konstanty et al. [18,19] chose three iron-based powders (Fe-Ni-Cu-Sn-C, Fe-Mn-Cu-Sn-C and Fe-Mn-Cu-Sn) to substitute the conventional WC-Co metal matrices for diamond tools.

To improve the quality and efficiency of diamond cutting wheels, multi-walled carbon nanotube was employed to reinforce the mechanical properties of the $\mathrm{Cu}$ and Fe based metallic composite [20]. It is believed that carbon nanotube can decrease the grain size of the binders, so as to improve the service performance of diamond wheels. Zaitsev et al. [21] found that diamond tools with dispersed $\mathrm{WC}$ and $\mathrm{ZrO}_{2}$ nanoparticles can improve tools service performance remarkably, when the tools are used to cut reinforced concrete. de Oliveira et al. [22] asserted that $\mathrm{Fe}-\mathrm{Cu}$ based bonds with an addition of $1 \mathrm{wt} . \%$ of $\mathrm{SiC}$, may be used for marble cutting diamond tools.

Previous studies indicate that a metal matrix often contains several different kinds of metal powders, whose hardness, density, melting temperature, particle sizes, etc. vary wildly [23]. Among these, the melting temperature of $\mathrm{Cu}$ and $\mathrm{Cu}$-alloys are approximately $900{ }^{\circ} \mathrm{C}$, while $\mathrm{Co}, \mathrm{Ni}, \mathrm{Fe}$ and $\mathrm{Mn}$ powders are around $1200-1500^{\circ} \mathrm{C}$. Thus, the formers are usually used as filling phases, and the latters are usually used as bonding phases. Additionally, with the popularization of all-hydraulic drill rig in geological exploration, and the increasing well depth of oil and gas drilling, WC has been altered from the conventional particle reinforced material to a primary content in hot pressed impregnated diamond bit [24-26].

During the hot-pressed sintering process, WC presents as a solid state, $\mathrm{Fe}, \mathrm{Co}, \mathrm{Ni}$ and $\mathrm{Mn}$ present as a thermoplastic state, while $\mathrm{Cu}$ or $\mathrm{Cu}$-alloy is the only liquid state. Therefore, the content of filling phase (e.g., $\mathrm{Cu}$, or $\mathrm{Cu}$-alloy) will be one of the key elements to diamond tools' service performance, and the aims of this paper are to figure out the effect laws and mechanisms of the filling phase content on hot-pressed WC based metal matrix composite (MMC).

\section{Experimental Procedure}

\subsection{Materials}

Compositions and their main physical properties of the WC based MMC in this study are shown in Table 1. Among these, WC has the best thermal conductivity, elasticity modulus, high hardness, and optimal coefficient of linear expansion, so it is used for improving the hardness and abrasive resistance of composite [27]. Ni and Co are used for improving the bending strength and impact toughness of composite, because both of them are good at ductility and toughness [28]. Additionally, by interfusion with $\mathrm{Cu}$ during the sintering process, $\mathrm{Ni}$ can minimize the spilling of liquid $\mathrm{Cu}$, thus enhancing the strength of the composite. Liquid $\mathrm{Cu}$, or $\mathrm{Cu}$ alloy is used as the filling phase, to bond all other solids, or thermoplastic materials (i.e., $\mathrm{WC}, \mathrm{Ni}, \mathrm{Co}, \mathrm{Mn}$, diamond grits, etc.) together.

Since the sintering temperature is usually lower than $1000^{\circ} \mathrm{C}$, which is insufficient to melt other materials except 663-Cu. Assume that all of the unfused metal powder particles are a sphere, and are encapsulated within the liquid $\mathrm{Cu}$ alloys discretely during the sintering process. Keep the volume contents of $\mathrm{Ni}, \mathrm{Co}$ and $\mathrm{Mn}$ as constant, vary the contents of WC and 663-Cu accordingly, and the obtained six WC based MMC sequences are listed in Table 2. As shown in Table 2, with a certain amount of filling phase volume, the average cooper foil thickness around each single unfused metal particle can be theoretically calculated. 
Table 1. Main physical properties of WC based metal matrix.

\begin{tabular}{cccccc}
\hline \multirow{2}{*}{ Properties } & \multicolumn{5}{c}{ Metal Powders for WC Based Matrix } \\
\cline { 2 - 6 } & WC & $\mathbf{6 6 3 - C \mathbf { C u } ^ { \mathbf { 1 } }}$ & $\mathbf{N i}$ & $\mathbf{C o}$ & $\mathbf{M n}$ \\
\hline Density $\left(\mathrm{g} / \mathrm{cm}^{3}\right)$ & 15.63 & 8.82 & 8.90 & 8.70 & 7.43 \\
Melting temperature $\left({ }^{\circ} \mathrm{C}\right)$ & 2785 & 900 & 1455 & 1495 & 1246 \\
Average size $(\mu \mathrm{m})$ & 4 & 75 & 45 & 2 & 75 \\
\hline $1^{1}$ The composition of $663-\mathrm{Cu}$ is $\mathrm{Cu}_{85} \mathrm{Sn}_{6} \mathrm{Zn}_{6} \mathrm{~Pb}_{3}$.
\end{tabular}

Table 2. Metal matrices with different percentages of filling phase.

\begin{tabular}{|c|c|c|c|c|c|c|c|c|c|c|c|}
\hline \multirow{3}{*}{$\begin{array}{l}\text { Sequence } \\
\text { Number }\end{array}$} & \multicolumn{10}{|c|}{ MMC Sequences } & \multirow{3}{*}{$\begin{array}{c}\text { Average Copper Foil } \\
\text { Thickness }(\mu \mathrm{m})\end{array}$} \\
\hline & \multicolumn{5}{|c|}{ (vol.\%) } & \multicolumn{5}{|c|}{ (wt.\%) } & \\
\hline & WC & 663-Cu & $\mathrm{Ni}$ & Co & Mn & WC & $663-\mathrm{Cu}$ & $\mathrm{Ni}$ & Co & Mn & \\
\hline 1 & 50 & 30 & 10 & 5 & 5 & 64 & 22 & 9 & 4 & 4 & 0.56 \\
\hline 2 & 45 & 35 & 10 & 5 & 5 & 60 & 26 & 8 & 4 & 3 & 0.69 \\
\hline 3 & 40 & 40 & 10 & 5 & 5 & 54 & 31 & 8 & 4 & 3 & 0.83 \\
\hline 4 & 35 & 45 & 10 & 5 & 5 & 49 & 36 & 8 & 4 & 3 & 0.98 \\
\hline 5 & 30 & 50 & 10 & 5 & 5 & 43 & 41 & 8 & 4 & 3 & 1.16 \\
\hline 6 & 25 & 55 & 10 & 5 & 5 & 37 & 46 & 7 & 4 & 3 & 1.36 \\
\hline
\end{tabular}

\subsection{Samples Preparation}

Three kinds of WC based MMC samples with different dimensions were fabricated by hot pressing to test their relative density, Rockwell hardness, abrasion weight loss, bending strength and impact toughness. An automatic controlled resistor furnace (SM-100A) was used for preparing samples. Detailed sample dimensions and sintering parameters were shown in Table 3. Different metal powders were mixed by a ball mill blender mixer for $10 \mathrm{~h}$, before being loaded into graphite molds for hot pressing sintering.

Table 3. Dimensions and sintering parameters for different samples.

\begin{tabular}{cccc}
\hline Tests & $\begin{array}{c}\text { Hardness/Abrasion } \\
\text { Weight Loss }\end{array}$ & $\begin{array}{c}\text { Bending Strength/Relative } \\
\text { Density }\end{array}$ & $\begin{array}{c}\text { Impact } \\
\text { Toughness }\end{array}$ \\
\hline Dimensions $(\mathrm{mm} \times \mathrm{mm} \times \mathrm{mm})$ & $8.5 \times 8.5 \times 15$ & $30 \times 5 \times 5$ & $55 \times 10 \times 10$ \\
Sintering temperature $\left({ }^{\circ} \mathrm{C}\right)$ & 985 & 985 & 985 \\
Sintering pressure $(\mathrm{MPa})$ & 15 & 15 & 15 \\
Sintering retention time $(\mathrm{min})$ & 3 & 2.5 & 5 \\
\hline
\end{tabular}

Besides, diamond reinforced composite (DRC) samples were made to find out the effects of the filling phase content on the holding force coefficient (HFC) of the WC based MMC to diamond grits, as well as the embedding occurrence of diamond grits within it. The samples dimension is $30 \mathrm{~mm} \times 5 \mathrm{~mm} \times 5 \mathrm{~mm}$, and the diamond concentration of DRC samples is $25 \mathrm{vol} . \%$, with an average particle size of 250 to $270 \mu \mathrm{m}$, i.e., 50 to 60 meshes.

The HFC is defined as follows $[29,30]$ :

$$
H F C=\sigma_{2} / \sigma_{1} \times 100 \%,
$$

where, $\sigma_{1}$ and $\sigma_{2}$ are the bending strengths of the MMC and DRC samples, respectively.

\subsection{Tests}

Under normal atmospheric, humidity and room temperature, Rockwell hardness tester (HR-150A, Shandong Yexian Testing Machine Factory, Jinan, Shandong, China), high speed friction and abrasion 
tester (MG2000,Xuanhua Kehua Testing Machine Co., Ltd., Zhangjiakou, Jiangsu, China), PC controlled universal testing machine (CTM2500, Shanghai Xieqiang Instrument Technology Co., Ltd., Shanghai, China) and pendulum impact testing machine (PTM2450, Shenzhen SUNS Technology Stock Co., Ltd. Shenzhen, China) were employed to measure the hardness, abrasion weight loss, bending strength and impact toughness of the WC based samples respectively. The relative density was measured according to Archimedes methods, and is defined as the ratio of MMC's actual density to its theoretical density.

It should be noted that, during the Rockwell hardness test, the upper and lower surfaces of each sample should be polished at first, and then measured three times on each surface. In the abrasion weight loss test, the samples were wear against white corundum grinding wheels (120 meshes), with a vertical force of $200 \mathrm{~N}$ and spindle's rotate speed of $200 \mathrm{rpm}$. The distance between the samples and the center of the rotary shaft was $30 \mathrm{~mm}$, and the wear duration was $2 \mathrm{~min}$. In the bending strength test, the span was $24.5 \mathrm{~mm}$ and the loading speed was $20 \mathrm{~N} / \mathrm{s}$. In the impact toughness test, the pendulum angle was $-150^{\circ}$, with pendulum energy of $450 \mathrm{~J}$, estimated absorption energy of $20 \mathrm{~J}$, and energy loss correction value of 0.845 .

\section{Results and Discussion}

\subsection{Mechanical Properties}

The main mechanical properties of different sequences were shown in Figure 1, and each test point in Figure 1 represents the average values of three samples, ensuring the accuracy of the test results.

As shown in Figure 1a, the relative densities of both MMC samples and DRC samples first increased with the amount of 663-Cu, and then monotonically decreased. MMC samples showed the highest and lowest relative densities at sequence no. 2 and no. 6 , with the values being $98.39 \%$ and $85.22 \%$ respectively while DRC samples got the highest and lowest relative densities at the same sequence number as MMC, with the values being $98.02 \%$ and $86.75 \%$ respectively. It should be noted that the lowest value at sequence no. 6 was further lowered by the filling phase spilling to a certain degree, which was attributed to the high sintering temperature.

From Figure 1b, it can be found that the Rockwell hardness and abrasion weight loss of the MMC samples increased with the amount of 663-Cu at first, and then monotonically declined, kind of like the effect laws of relative density. However, the critical filling phase percentage changed, with the highest hardness and abrasion weight loss at sequence no. 3. The highest and lowest Rockwell hardness values of MMC were HRB 111.21 and HRB 98.63 respectively. According to its test principle, hardness is mainly determined by the compositions of sample surface [26,31]. In other words, it is determined by the volume ratio of WC to 663-Cu. When $W^{\prime}$ 's volume percentage was more than $663-\mathrm{Cu}$, it was dominated by stiff WC particles, rather than soft $663-\mathrm{Cu}$, and vice versa. Simultaneously, appropriate 663-Cu can increase MMC's relative density, while suitable WC can work as reinforced particles to improve MMC's hardness and wear resistance.

As shown in Figure 1c, the bending strength of MMC was enhanced with the increase of 663-Cu initially, and then dropped monotonically, in line with Rockwell hardness. Nevertheless, the bending strength of DRC declined with the increase of 663-Cu overall. Within the tested range of filling phase percentages in this study, the bending strength of DRC was as low as 350-605 MPa, which was remarkably lower than the bending strength of MMC, namely, from 725 to $1265 \mathrm{MPa}$. The reason might be that the addition of diamond grits aggravated the heterogeneity of the sample surface, especially since the bending strength test is very sensitive to samples' surface defects.

The dramatical amplitude reduction of bending strength resulted in weak HFC of the WC based MMC. As shown in Figure 1d, most HFCs were weaker than 50\%, namely, ranged from 38.99\% to 57.08\%. The HFCs declined first with the increase of the filling phase amount, and then improved slightly. The critical point came from sequence no. 4, with the filling phase concentration of $45 \mathrm{vol} . \%$, or $36 \mathrm{wt} . \%$. Besides, Figure $1 \mathrm{~d}$ also showed that the impact toughness of MMC improved with the increase of 
filling phase amount in general, with values ranged from 11.36 to $13.44 \mathrm{~J} / \mathrm{cm}^{2}$. The improvement of impact toughness was due to the good ductility of 663-Cu.
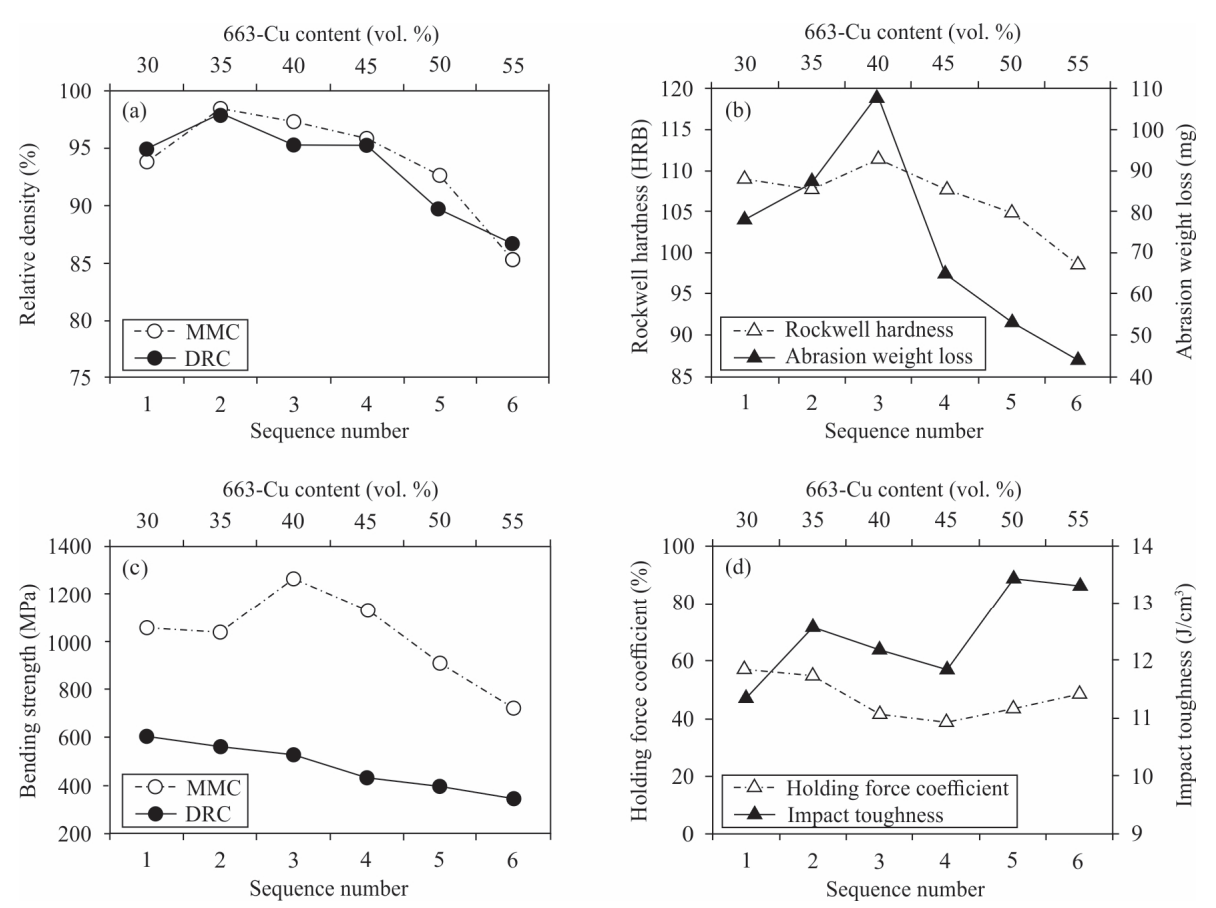

Figure 1. Main mechanical properties of the WC based composites with different filling phase percentages: (a) relative density; (b) Rockwell hardness and abrasion weight loss; (c) bending strength and (d) holding force coefficient and impact toughness.

In summary, compared with sequence no. 1, the significances of the filling phase percentages on the main mechanical properties of WC based MMC are as follows in descending order: abrasion weight loss, bending strength, HFC, impact toughness, Rockwell hardness and relative density.

\subsection{Microstructure Characterization}

Microstructure of the WC based MMC samples after the bending strength tests were shown in Figure 2. According to the physical properties of metal powders in Table 1, as well as the matrices compositions in Table 2, it is obvious that the white fractions on the fracture surfaces are micro WC particles.

As shown in Figure 2a, the fracture surface of sequence no. 1 is apparently rugged, full of large fracture edges and fissures, which can be attributed to limited $663-\mathrm{Cu}$ of $30 \mathrm{vol} . \%$, or $22 \mathrm{wt} . \%$. Since WC is hardly going melt during the sintering process, with the addition of its high volume percentage, it is inadequate for the liquid cooper alloy to bond all the metal materials together. Therefore, a lack of liquid filling phase could result in micro crevices in some particular areas. During the bending strength test, cracks would be initiated from these crevices, and developed along with its direction of long axis, thus causing clumpy and irregular fracture surface.

From Figure $2 b, c$, it can be found that the fracture surfaces of sequence no. 2 and no. 3 tended to be flat, with the increase of 663-Cu. The width and depth of the micro crevices also diminished, improving the samples' relative density to a certain degree. Then, the increase of relative density gave rise to an overall increase trend of Rockwell hardness and bending strength when the volume percentage of $663-\mathrm{Cu}$ was no more $40 \mathrm{vol} . \%$. 

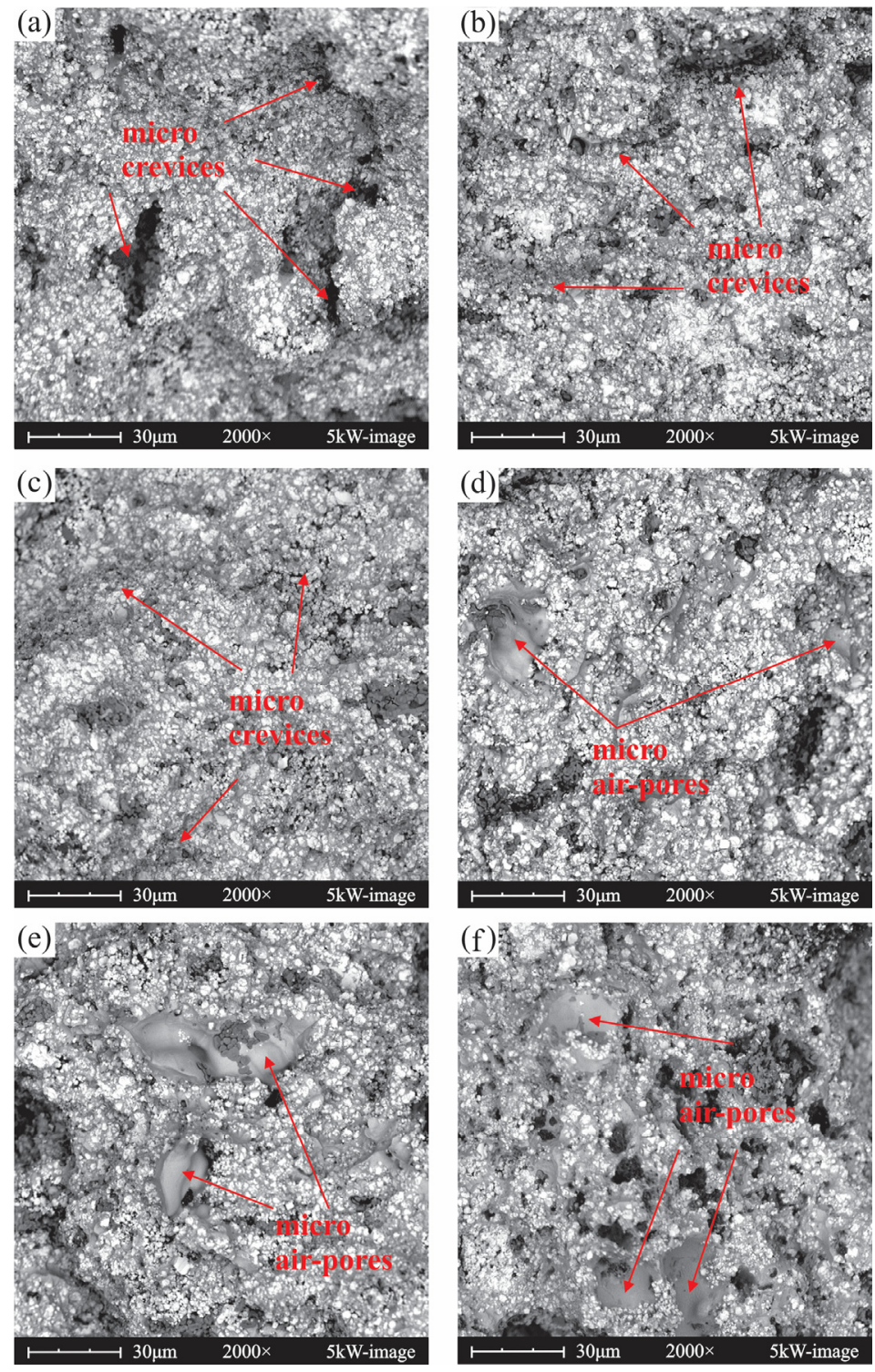

Figure 2. Fracture surfaces of MMC samples after bending strength tests $(2000 \times)$. (a) Sequence no. 1; (b) sequence no. 2; (c) sequence no. 3; (d) sequence no. 4; (e) sequence no. 5 and (f) sequence no. 6.

As shown from Figure $2 \mathrm{~d}-\mathrm{f}$, micro air-pores can be observed on the fracture surfaces when the 663-Cu amount was more than $45 \mathrm{vol} . \%$. Since the samples preparation in this study was under the normal atmospheric environment, it was inevitable that some air would remain within mixed metal powders, when the powders were loaded into graphite molds. During the sintering process, the remained air would expand and escape from the powders, due to the rise of heating temperature. However, a large amount of filling phase, for instance, more than $45 \mathrm{vol} . \%$ of $663-\mathrm{Cu}$, will melt into liquid at a relatively lower temperature $\left(900^{\circ} \mathrm{C}\right)$, and impede the escape efficiency of air by diminishing its escape routes. Therefore, some of the micro air bubbles will be encapsulated by liquid copper alloy during the sintering process, and result in micro air-pores on the fracture surface. The air-pores can be distinguished with the abovementioned micro crevices from width, depth, as well as their inner surface roughness. Furthermore, since the melting point of $663-\mathrm{Cu}$ is lower than the sintering temperature, the cooper alloy would melt into liquid before reaching the designated sintering temperature and pressure. Consequently, the liquid alloy might spill out of graphite mold under high sintering pressure, causing micro air pores and decline of relative density. 


\subsection{Diamond Retention}

The retention capacity of MMC to diamond is composed of physical adsorption force, mechanical inlaying force and chemical bonding force, in increasing order of significance [29]. For the diamond tools manufactured by powder metallurgy, the diamond retention is dominated by mechanical inlaying, while the intensity of chemical bonding is determined by matrix compositions and sintering technology [32,33]. In this study, the percentages of Ni, Co and Mn were constant in the six matrices, so the only reason for the reduction of HFC was the variation of WC and 663-Cu contents.

Figure 3 shows the morphologies of diamond grits embedded in MMC samples, as well as the enlarged views of their interfaces. It is obvious that liquid cooper alloy accumulated at the interface, and intensified along with the increase of 663-Cu content in the six sequences. As shown in Figure 3a, the interface is mainly composed of equally distributed WC particles and micro crevices. The liquid cooper alloy just existed at some small parts of the interface. With the increase of 663-Cu, the interface was gradually covered by liquid cooper alloy. From Figure $3 b$, it can be found that the WC particles aggregated to a certain degree, which could amplify its heterogeneity and worsen the diamond retention capacity. Figure $3 \mathrm{c}$ shows that the interface is totally covered by liquid cooper alloy, which indicates a good mechanical inlaying strength of the densified MMC to diamond grits.

According to a previous study [34], $\mathrm{Cu}$ and $\mathrm{Zn}$ are non-interacting metals to carbon, $\mathrm{Ni}$ and $\mathrm{Co}$ are moderately interacting metals to carbon, while $\mathrm{Mn}$ and $\mathrm{W}$ are carbide formers. As shown in Figure 1d, the HFC of WC based MMC to diamond grits declined with the increase of 663-Cu firstly, and then rose slightly. Since $\mathrm{Cu}$ did not show any tendency to interact with carbon, the $\mathrm{Cu}$ based matrix and diamond surface was theoretically untouched, and the diamond retention proved to be very weak [35]. However, since $\mathrm{W}$ is one of the carbide formers, the volume percentage of WC should play an important role in promoting the chemical bonding between MMC and diamond surface. Consequently, the reason for HFC reduction could be the decrease of the contact area between WC and diamond surface. Nevertheless, when the volume percentage of 663-Cu was more than that of WC, the liquid cooper alloy could enhance the mechanical inlaying strength of MMC to diamond grits, thus improving the HFC slightly.

\subsection{Wear Behavior}

Wear behavior is one of the main properties to judge a diamond tool's service performance, and it is affected by matrix compositions and manufacture technology at the same time [36]. Generally, stronger wear resistance indicates longer service life, while weaker wear resistance leads to higher processing efficiency.

Figure 4 shows the wear morphologies of MMC samples after pin-on-disc wear and friction test. Figure 4a displays a noticeable brittle failure area, which was caused by fatigue wear, and there were lots of powdery and clastic debris on the wear surface. At the same time, smooth plastic deformation trails could be observed from the wear surface. Therefore, the wear mechanism of sequence no. 1 was dominated by adhesive wear (e.g., smear) and coupling with fatigue wear.

With the increase of 663-Cu, most debris disappeared as shown in Figure $4 \mathrm{~b}$, while a conspicuous groove could be observed, though much of its space was filled with deformed matrix and chips. Consequently, the wear mechanism of sequence no. 2 was adhesive wear (e.g., scratching) and coupling with abrasive wear (e.g., scuffing). The wear surface of Figure 4c shows remarkable micro-cutting trails, with relatively wide and deep dimensions. Along the trails, there were continuous chips resulting from plastic deformation, and flatted by vertical loads and rotational motion. As a consequence, the wear mechanism of sequence no. 3 was dominated by abrasive wear (e.g., micro-cutting). 

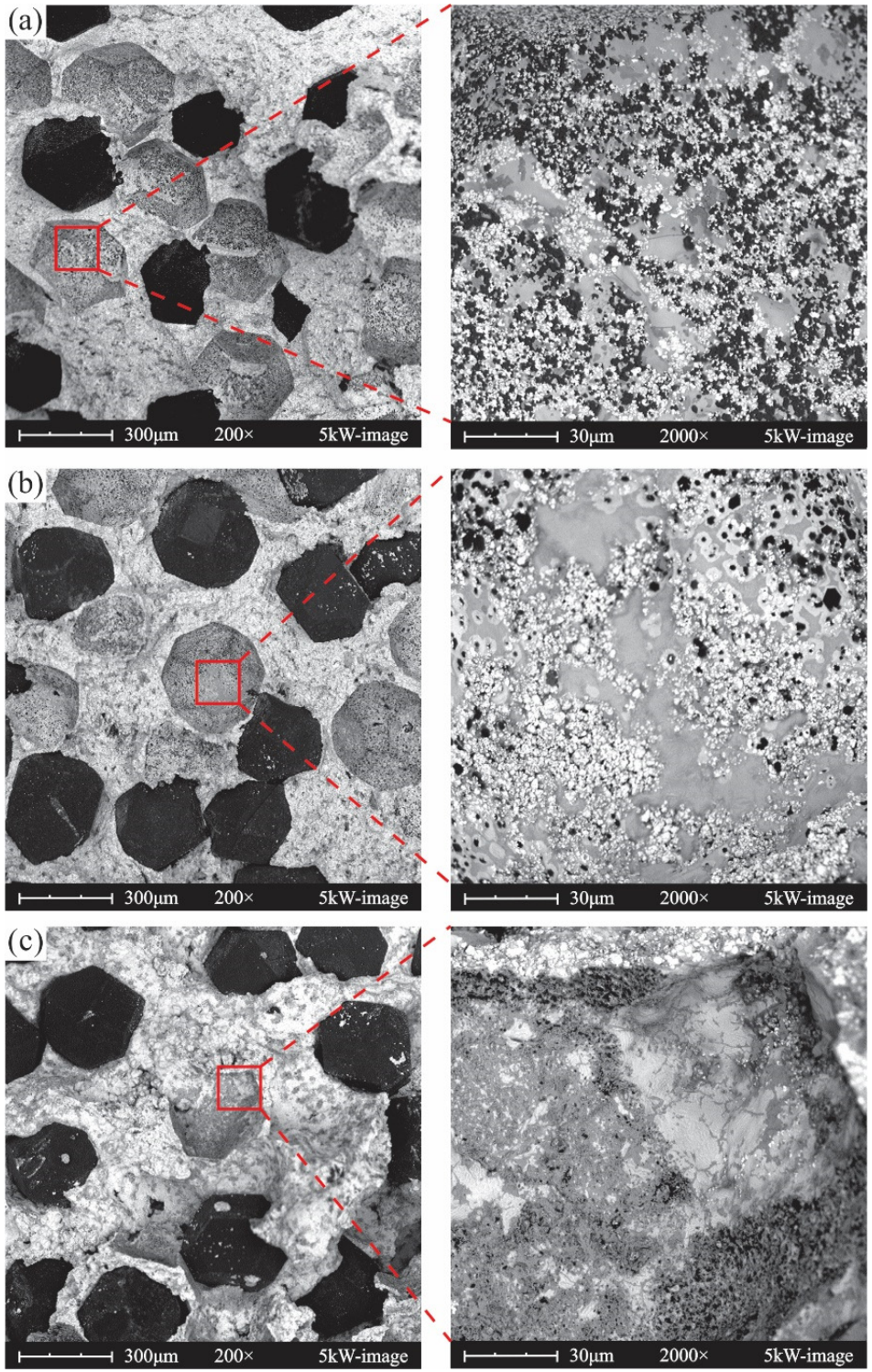

Figure 3. Morphologies of the fracture surfaces (200x) and diamond-metal matrix interfaces (2000x) of the diamond reinforced composite (DRC) samples after bending strength tests: (a) sequence no. 1 ; (b) sequence no. 4 and (c) sequence no. 6 .

As shown in Figure 4d, groove traces could be observed on the wear surface, though most of their space is mitigated by the matrix's plastic deformation, which was caused by cyclically repeated load and rational motion. A certain part of wear surface was also smooth and adhered with large fragmentation. Thus, the wear mechanism of sequence no. 4 was abrasive wear (e.g., micro-cutting) and adhesive wear (e.g., smear). The wear surface of Figure $4 \mathrm{e}$ was similar to that of Figure $4 \mathrm{~d}$, though most of the surface area was shown as scratching. The groove traces were shallower, narrower and discontinuous. The broken debris adhered to the wear surface was also smaller. Thus, the wear mechanism of sequence no. 5 was abrasive wear (e.g., scuffing), coupling with adhesive wear (e.g., scratching). 

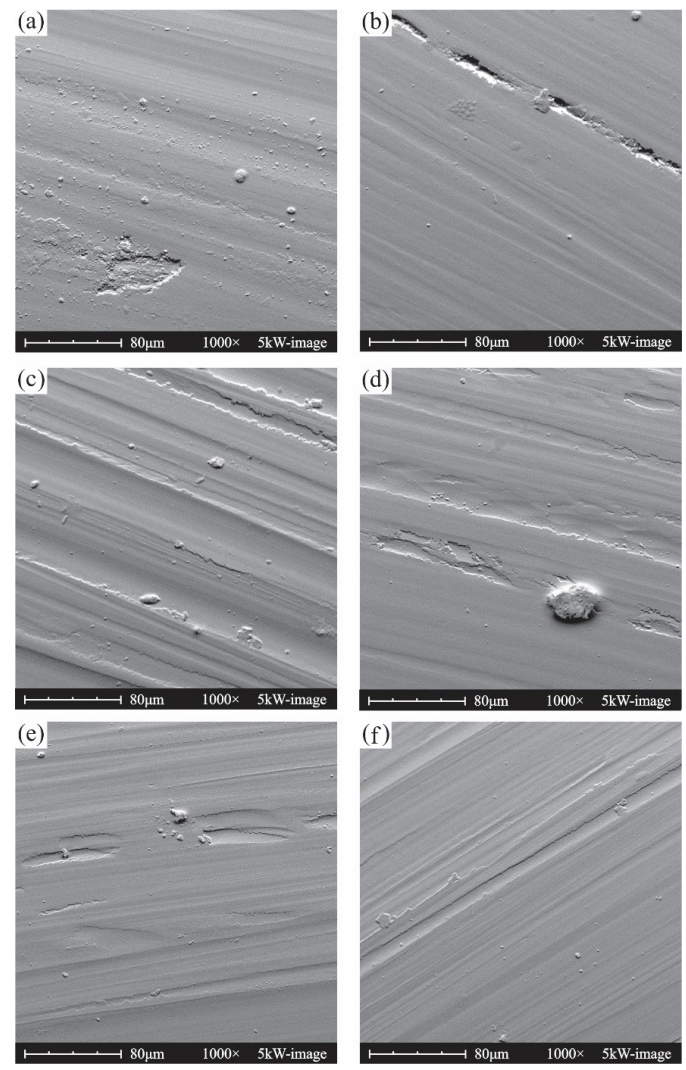

Figure 4. Wear morphologies of WC based metal matrix composite (MMC) samples after pin-on-disc tests. (a) Sequence no. 1; (b) sequence no. 2; (c) sequence no. 3; (d) sequence no. 4; (e) sequence no. 5 and (f) sequence no. 6 .

When the volume percentage of $663-\mathrm{Cu}$ increased to $55 \%$ in sequence no. 6, as shown in Figure $4 \mathrm{f}$, the wear surface seems comparatively smooth, with trivial scratching and smear trails. Besides, there were flatted, continuous chips along with the trails, which were caused by plastic deformation of the chips under vertical pressure. In consequence, the wear mechanism at this time was adhesive wear (e.g., scratching and smear).

Combining the affected laws of abrasion weight loss in Figure $1 \mathrm{~b}$ with wear behavior in Figure 4, it could be concluded that a lack of liquid filling phase during the sintering process would result in uneven distribution of 663-Cu, and weak bonding strength between different components of the WC based MMC. Therefore, the samples with much higher percentages of WC than 663-Cu, were relatively harder, while the ones with much more 663-Cu had better plasticity. As for the former, the powdery WC debris resulting from fatigue failure could serve as tiny abrasives during the pin-on-disc wear test. For the latter, $\mathrm{Cu}, \mathrm{Sn}$ and $\mathrm{Pb}$ are all soft metals, which can be employed as solid lubricants $[37,38]$, so the higher percentages of 663-Cu could protect the wear surface of the WC based MMC. However, it should be noted that those above mentioned inferences were obtained qualitatively, and accurate effect laws of WC and 663-Cu on the wear behavior should be further studied.

\section{Conclusions}

Drawing from the above analysis of the mechanical properties, microstructure, diamond retention and wear behavior of the WC-Cu based hot-pressing metal matrix composites, some noticeable conclusions could be obtained as follows:

(1) Increasing filling phase amount could improve MMC's mechanical properties when it was no more than $40 \mathrm{vol} . \%$, though a higher amount would result in a monotonously decline of the properties except impact toughness. 
(2) The filling phase amount was significant to the microstructure characteristics of MMC's fracture surface, and the appearance of micro crevices, or pores.

(3) Retention capacity of MMC to diamond declined with the increase of 663-Cu at first, and then improved slightly.

(4) Wear mechanism of a typical WC based MMC was mainly dominated by abrasive wear, while it tended to be altered into adhesive wear if it contained too much stiff WC, or self-lubricated $\mathrm{Cu}$.

Author Contributions: Writing—original draft preparation and data analysis, S.T. and X.F.; measurements and tests, C.L. (Chenglong Li) and H.S.; review and supervision, C.L. (Changping Li) and L.D.

Funding: This research was funded by the PetroChina Innovation Foundation, grant number 2016D-5007, -0307, the National Natural Science Foundation of China, grant numbers 41602373, 41672364 and 41972327, and the Renovation project of laboratory technique, China University of Geosciences, Wuhan, grant no. SJ-201708.

Conflicts of Interest: The authors declare no conflict of interest.

\section{References}

1. Tonshoff, H.K.; Hillmann-Apmann, H. Diamond tools for wire sawing metal components. Diam. Relat. Mater. 2002, 11, 742-748. [CrossRef]

2. Konstanty, J. Production parameters and materials selection of powder metallurgy diamond tools. Powder Metall. 2006, 4, 299-306. [CrossRef]

3. Franca, L.F.P.; Mostofi, M.; Richard, T. Interface laws for impregnated diamond tools for a given state of wear. Int. J. Rock Mech. Min. 2015, 73, 184-193. [CrossRef]

4. Sathish, S.; Ramkumar, S.; Geetha, M. Drilling performances and wear characteristics of coated drill bits during drilling reinforced concrete. Int. J. Appl. Ceram. Technol. 2018, 16, 1-10. [CrossRef]

5. Brook, B. Principles of diamond tool technology for sawing rock. Int. J. Rock Mech. Min. 2002, 39, 41-58. [CrossRef]

6. Tonshoff, H.K.; Hillmann-Apmann, H.; Asche, J. Diamond tools in stone and civil engineering industry: Cutting principles, wear and applications. Diam. Relat. Mater. 2002, 11, 736-741. [CrossRef]

7. Huang, H.; Huang, G.; Xu, X.; Huang, H. An experimental study of machining characteristics and tool wear in the diamond wire sawing of granite. Proc. Inst. Mech. Eng. Part J. Eng. Manuf. 2013, 7, 943-953. [CrossRef]

8. Wang, J.-L.; Zhang, S.-H. A new diamond bit for extra-hard, compact and nonabrasive rock formation. J. Cent. South Univ. 2015, 22, 1456-1462. [CrossRef]

9. Oliveira, F.A.C.; Anjinho, C.A.; Coelho, A.; Amaral, P.M.; Coelho, M. PM materials selection: The key for improved performance of diamond tools. Met. Powder. Rep. 2017, 5, 339-344. [CrossRef]

10. Liu, W.; Pan, F.; Yang, H.; Yu, G.; Chen, Z.; Tan, S. Influence of magnetic treatment parameters on mechanical properties of hot-pressing sintering iron-based diamond bit matrix. Geol. Sci. Technol. Inf. 2018, 5, 269-274. [CrossRef]

11. Nitkiewicz, Z.; Swierzy, M. Tin influence on diamond-metal matrix hot-pressed tools for stone cutting. J. Mater. Process. Tech. 2006, 175, 306-315. [CrossRef]

12. del Villar, M.; Muro, P.; Sanchez, J.M.; Iturriza, I.; Castro, F. Consolidation of diamond tools using Cu-Co-Fe based alloys as metallic binders. Powder Metall. 2001, 1, 82-90. [CrossRef]

13. Spriano, S.; Chen, Q.; Settineri, L.; Bugliosi, S. Low content and free cobalt matrixes for diamond tools. Wear 2005, 259, 1190-1196. [CrossRef]

14. Zak-Szwed, M.; Konstanty, J.; Ratuszek, W. Properties of Fe-Cu matrices for diamond impregnated tools. Industrial Diamond Review. 2008, 8, 31-34.

15. Dai, H.; Wang, L.; Zhang, J.; Liu, Y.; Wang, Y.; Wang, L.; Wan, X. Iron based partially pre-alloyed powders as matrix materials for diamond tools. Powder Metall. 2015, 2, 83-86. [CrossRef]

16. Yu, G.; Jiao, X.; Li, J.; Chen, H.; Tan, S.; Fang, X. Effect mechanism of formula pre-alloying on improving hot-pressed diamond bit iron-rich matrix performance. Geol. Sci. Tech. Inf. 2018, 5, 260-268.

17. Loginov, P.A.; Sidorenko, D.A.; Shvyndian, N.V.; Sviridova, T.A.; Churyumov, A.Y.; Levashov, E.A. Effect of $\mathrm{Ti}$ and $\mathrm{TiH} 2$ doping on mechanical and adhesive properties of Fe-Co-Ni binder to diamond in cutting tools. Int. J. Refract. Met. Hard Mater. 2019, 79, 69-78. [CrossRef] 
18. Konstanty, J.; Ramanski, A.; Baczek, E.; Tyrala, D. New wear resistant iron-base matrix materials for the fabrication of sintered diamond tools. Arch. Metall. Mater. 2015, 2, 633-637. [CrossRef]

19. Konstanty, J.S.; Baczek, E.; Romanski, A.; Tyrala, D. Wear-resistant iron-based Mn-Cu-Sn matrix for sintered diamond tools. Powder Metall. 2018, 1, 43-49. [CrossRef]

20. Sidorenko, D.; Mishnaevsky, L., Jr.; Levashov, E.; Loginov, P.; Petrzhik, M. Carbon nanotube reinforced metal binder for diamond cutting tools. Mater. Design. 2015, 83, 536-544. [CrossRef]

21. Zaitsev, A.A.; Sidorenko, D.A.; Levashov, E.A.; Kurbatkina, V.V.; Andreev, V.A.; Rupasov, S.I.; Sevast'yanov, P.V. Diamond tools in metal bonds dispersion- strengthened with nanosized particles for cutting highly reinforced concrete. J. Superhard Mater. 2010, 6, 423-431. [CrossRef]

22. de Oliveira, L.J.; Bobrovnitchii, G.S.; Filgueira, M. Processing and characterization of impregnated diamond cutting tools using a ferrous metal matrix. Int. J. Refract. Hard Mater. 2007, 25, 328-335. [CrossRef]

23. Zeren, M.; Karagöz, Ş. Sintering of polycrystalline diamond cutting tools. Mater. Design. 2007, 28, 1055-1058. [CrossRef]

24. Huusgard, P.; Caycedo, A.; Cai, M. Diamond-impregnated drill bit performance in the lower basalt series offshore the Faroe Islands. A case study based on basalt outcrop testing. In Proceedings of the SPE North Africa Technical Conference and Exhibition, Cairo, Egypt, 14-16 September 2015; SPE-175880-MS.

25. Murillo, R.; Guzman Rangel, F.G.; Melo, E.; Luna Gonzalez, O.; Romero, D.A.; Beltran, D. Turbodrilling system and diamond-impregnated bit saved three trips in a hard carbonate reservoir. In Proceedings of the SPE Latin America and Caribbean Mature Fields Symposium, Salvador, Brazil, 15-16 March 2017; SPE-184924-MS.

26. Tan, S.; Zhang, W.; Duan, L.; Pan, B.; Rabiei, M.; Li, C. Effects of MoS2 and WS2 on the matrix performance of WC based impregnated diamond bit. Tribol. Int. 2019, 131, 174-183. [CrossRef]

27. Wang, J.; Li, N. The Complete Book of Latest Standards and Applied Technologies of Diamond and Diamond Products, 1st ed.; Heilongjiang Culture \& Audio \& Video Publishing House: Harbin, China, 2004; pp. 32-35.

28. Sun, Y.; Song, Y. Manufacturing Theory and Practice of Diamond Tools, 1st ed.; Zhengzhou University Press: Zhengzhou, China, 2004; pp. 3-9.

29. Zhao, X.; Duan, L. A review of the diamond retention capacity of metal bond matrices. Metals. 2018, 8, 307. [CrossRef]

30. Zhao, X.; Li, J.; Duan, L.; Tan, S.; Fang, X. Effect of Fe-based pre-alloyed powder on the microstructure and holding strength of impregnated diamond bit matrix. Int. J. Refract. Met. Hard Mater. 2019, 79, 115-122. [CrossRef]

31. Liu, M.; Liu, S. Mechanical Performance Handbook of Metal Materials, 1st ed.; China Machine Press: Beijing, China, 2011; pp. 75-84.

32. Zeren, M.; Karagöz, Ş. Defect characterization in the diamond cutting tools. Mater. Charact. 2006, 57, 111-114. [CrossRef]

33. Romanski, A. Factors affecting diamond retention in powder metallurgy diamond tools. Arch. Metall. Mater. 2010, 4, 1073-1081. [CrossRef]

34. Artini, C.; Muolo, M.L.; Passerone, A. Diamond-metal interfaces in cutting tools: A review. J. Mater. Sci. 2012, 47, 3252-3264. [CrossRef]

35. Lin, C.-S.; Yang, Y.-L.; Lin, S.-T. Performances of metal-bond diamond tools in grinding alumina. J. Mater. Process. Tech. 2008, 201, 612-617. [CrossRef]

36. Dhokey, N.B.; Utpat, K.; Gosavi, A.; Dhoka, P. Hot-press sintering temperature response of diamond cutting tools and its correlation with wear mechanism. Int. J. Refract Met. Hard Mater. 2013, 36, 289-293. [CrossRef]

37. Donnet, C.; Erdemir, A. Solid lubricant coatings: Recent developments and future trends. Tribol. Lett. 2004, 3, 389-397. [CrossRef]

38. Furlan, K.P.; de Mello, J.D.B.; Klein, A.N. Self-lubricating composites containing $\mathrm{MoS}_{2}$ : A review. Tribol. Int. 2018, 120, 280-298. [CrossRef]

(C) 2019 by the authors. Licensee MDPI, Basel, Switzerland. This article is an open access article distributed under the terms and conditions of the Creative Commons Attribution (CC BY) license (http://creativecommons.org/licenses/by/4.0/). 